Check for updates

Cite this: RSC Adv., 2021, 11, 19121

Received 24th March 2021

Accepted 16th May 2021

DOI: $10.1039 / \mathrm{d} 1 \mathrm{ra0} 2347 \mathrm{k}$

rsc.li/rsc-advances

\title{
Tandem imine formation via auto-hydrogen transfer from alcohols to nitro compounds catalyzed by a nanomagnetically recyclable copper catalyst under solvent-free conditions $\uparrow$
}

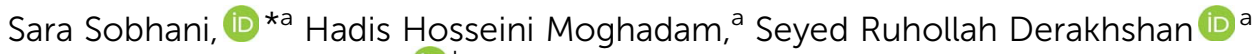 \\ and José Miguel Sansano (DD ${ }^{\mathrm{b}}$
}

\begin{abstract}
A direct imination reaction was developed by tandem reaction of alcohols and nitro compounds in the presence of $\mathrm{Cu}$-isatin Schiff base- $\gamma-\mathrm{Fe}_{2} \mathrm{O}_{3}$ as a nanomagnetically recyclable catalyst under solvent-free conditions. By this method, various imines were prepared in good to high yields from one-pot reaction of various alcohols (primary aromatic and aliphatic) and nitro compounds (aromatic and aliphatic) via an auto-hydrogen transfer reaction. Use of an inexpensive and easily reusable catalyst, without requiring any additives or excess amounts of benzyl alcohol as the reaction solvent are the other advantages of this method. This catalytic system has the merits of cost effectiveness, environmental benignity, excellent recyclability and good reproducibility.
\end{abstract}

\section{Introduction}

Imines are crucial intermediates in the synthesis of biologically active nitrogen compounds, such as $\beta$-lactams, dyes, fragrances, pharmaceuticals, fungicides, and agricultural chemicals. ${ }^{1}$ The $\mathrm{C}=\mathrm{N}$ bond in imines has electrophilic properties and is widely used in organic transformations such as reduction, addition, cyclization, and aziridination reactions. ${ }^{2}$ Traditionally, imines are produced from the condensation of primary amines with carbonyl compounds. ${ }^{3}$ In recent years, much attention has been paid to tandem processes as an attractive synthetic concept for improving overall process efficiency and reducing waste production by converting simple starting materials into more complex products in a single reaction vessel. ${ }^{4}$ In this regard, tandem synthesis of imines from alcohols and nitro compounds is a more advantageous method than traditional procedures, because alcohols are much more stable and readily available starting materials. ${ }^{5}$ The process involves selective oxidation of benzyl alcohol to benzaldehyde followed by the coupling reaction of amines with benzaldehyde. ${ }^{6}$ From the standpoint of sustainable development, an atom-economic, "green" and operationally convenient method, the synthesis of imines from nitro compounds is highly desirable. ${ }^{7}$ In this

${ }^{a}$ Department of Chemistry, College of Sciences, University of Birjand, Birjand, Iran. E-mail: ssobhani@birjand.ac.ir; sobhanisara@yahoo.com

${ }^{b}$ Departamento de Química Orgánica, Facultad de Ciencias, Centro de Innovación en Química Avanzada (ORFEO-CINQA), Instituto de Síntesis Orgánica (ISO), Universidad de Alicante, Apdo. 99, 03080-Alicante, Spain

$\dagger$ Electronic supplementary information (ESI) available: The synthesis and analysis of the catalyst. See DOI: $10.1039 / \mathrm{d} 1 \mathrm{ra02347 \textrm {k }}$ regard, the borrowing-hydrogen methodology (auto-hydrogen transfer), which transfers hydrogen from readily available alcohols to nitro compounds to produce amines as well as valuable aldehydes, provides a promising alternative to the existing method for the synthesis of imines. ${ }^{8}$ Some complexes and compounds derived from transition metals of the second and third rows, such as ruthenium, ${ }^{9}$ palladium, ${ }^{10}$ silver $^{11}$ iridium $^{12}$ and gold ${ }^{13}$ have been introduced as promoters of this strategy of the imine synthesis. However, the toxicities, pricing, and stability of these metals prohibit their general use for industrial purposes. ${ }^{14}$ Surprisingly, there is only one report on the use of copper for imines formation via auto-hydrogen transfer, ${ }^{15}$ although copper is a low cost, easily available and

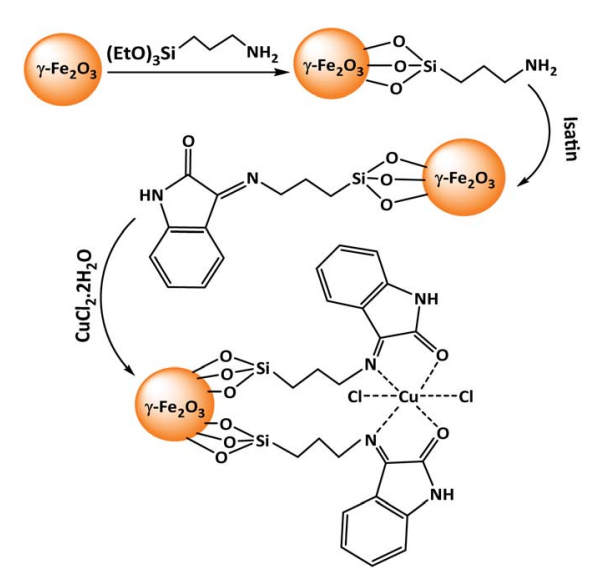

Scheme 1 Preparation of $\mathrm{Cu}$-isatin Schiff base- $\gamma-\mathrm{Fe}_{2} \mathrm{O}_{3}$. 
relatively environmentally benign metal. This reported method suffers from severe problems related to the use of a toxic organic solvent, excess amount of the base, high temperature, and requiring prolonged reaction time (3 days).

In continuation of our efforts on the introduction of new heterogeneous catalysts for organic transformations, ${ }^{\mathbf{1 6}}$ we have recently synthesized Cu-isatin Schiff base- $\gamma-\mathrm{Fe}_{2} \mathrm{O}_{3}$ (Scheme 1) and used it as a new heterogeneous catalyst for the synthesis of bis(indolyl)methanes and bis(pyrazolyl)methanes. ${ }^{17}$ Herein, in this paper, we have expanded the scope of application of this catalyst for the tandem imine formation by auto-hydrogen transfer from alcohols to nitro compounds under solvent-free conditions.

\section{Result and discussion}

$\mathrm{Cu}$-isatin Schiff base- $\gamma-\mathrm{Fe}_{2} \mathrm{O}_{3}$ as a nanomagnetically heterogeneous catalyst was synthesized according to our previously reported method. ${ }^{16}$ Cu-isatin Schiff base- $\gamma-\mathrm{Fe}_{2} \mathrm{O}_{3}$ as a nanomagnetically heterogeneous catalyst, was synthesized by functionalization of $\gamma-\mathrm{Fe}_{2} \mathrm{O}_{3}$ with 3-aminopropyltriethoxysilane and then the reaction with isatin to produce isatin Schiff base- $\gamma$ $\mathrm{Fe}_{2} \mathrm{O}_{3}$ followed by the reaction with dissolving $\mathrm{CuCl}_{2} \cdot 2 \mathrm{H}_{2} \mathrm{O}$ in methanol (Scheme 1).

The catalyst was characterized by a series of techniques such as FT-IR, XRD, TGA, TEM, SEM, VSM, ICP and elemental analysis.

The FT-IR spectra of (a) amino-functionalized $\gamma-\mathrm{Fe}_{2} \mathrm{O}_{3}$, (b) isatin Schiff base- $\gamma-\mathrm{Fe}_{2} \mathrm{O}_{3}$ and Cu-isatin Schiff base- $\gamma-\mathrm{Fe}_{2} \mathrm{O}_{3}$ are exhibited in Fig. 1. The FT-IR spectrum of amino-functionalized $\gamma-\mathrm{Fe}_{2} \mathrm{O}_{3}$ exhibited a broad band at around $550-670 \mathrm{~cm}^{-1}$ due to the stretching vibrations of $\mathrm{Fe}-\mathrm{O}$. The appeared peaks at 1085 , 3438,3480 and around $2869-2906 \mathrm{~cm}^{-1}$ in the FT-IR spectrum of amino-functionalized $\gamma-\mathrm{Fe}_{2} \mathrm{O}_{3}$ are related to $\mathrm{C}-\mathrm{N}, \mathrm{N}-\mathrm{H}$ and $\mathrm{C}-\mathrm{H}$ stretching modes of the alkyl chain, respectively. $\mathrm{N}-\mathrm{H}$ bending was observed at $1631 \mathrm{~cm}^{-1}$ (Fig. 1a). New bands at 1455,1608 and $1718 \mathrm{~cm}^{-1}$ in the FT-IR spectrum of isatin Schiff base- $\gamma-\mathrm{Fe}_{2} \mathrm{O}_{3}$ (Fig. 1b) refer to the $\mathrm{C}=\mathrm{C}, \mathrm{C}=\mathrm{N}$ and $\mathrm{C}=\mathrm{O}$ stretching vibrations, respectively. These bands proved that isatin has been successfully reacted with amino-functionalized

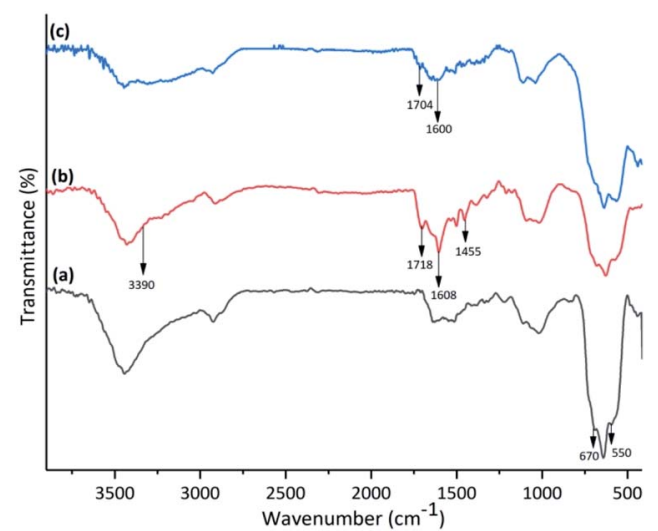

Fig. 1 FT-IR spectra of (a) amino-functionalized $\gamma-\mathrm{Fe}_{2} \mathrm{O}_{3}$, (b) isatin Schiff base- $\gamma-\mathrm{Fe}_{2} \mathrm{O}_{3}$ and (c) $\mathrm{Cu}$-isatin Schiff base- $\gamma-\mathrm{Fe}_{2} \mathrm{O}_{3}$.

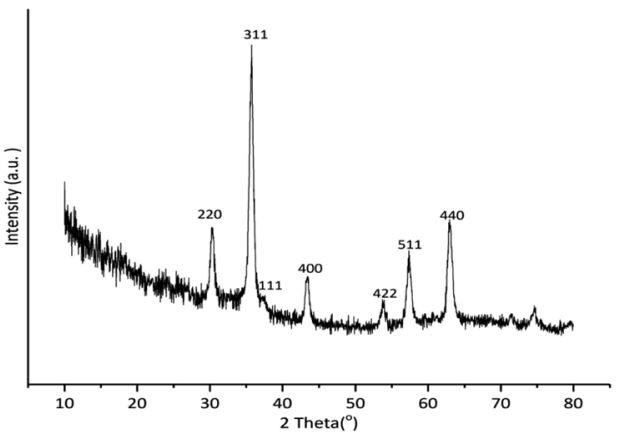

Fig. 2 XRD pattern of Cu-isatin Schiff base $-\gamma-\mathrm{Fe}_{2} \mathrm{O}_{3}$.

$\gamma-\mathrm{Fe}_{2} \mathrm{O}_{3}$. N-H stretching band of the amide group in isatin overlapped with the broad $\mathrm{O}-\mathrm{H}$ band, which was found at $3390 \mathrm{~cm}^{-1}$. In the FT-IR spectra of Cu-isatin Schiff base- $\gamma-\mathrm{Fe}_{2} \mathrm{O}_{3}$ (Fig. 1c), the $\mathrm{C}=\mathrm{N}$ and $\mathrm{C}=\mathrm{O}$ stretching frequencies were shifted to the lower wave numbers $\left(1600,1704 \mathrm{~cm}^{-1}\right)$, which showed the successful coordination of nitrogen and oxygen to the metal center.

As presented in Fig. 2, the reflection planes of (2 200$),\left(\begin{array}{lll}3 & 1 & 1\end{array}\right)$, (1 111 ), (4 00 ) , (4 22 2), (5 111 ) and (4 40 ) at $2 \theta=30.3^{\circ}, 35.7^{\circ}, 39.9^{\circ}$, $43.4^{\circ}, 53.8^{\circ}, 57.4^{\circ}$ and $63.0^{\circ}$ were readily recognized in the XRD pattern of $\mathrm{Cu}$-isatin Schiff base- $\gamma-\mathrm{Fe}_{2} \mathrm{O}_{3}$. These characteristic peaks matched with those of standard $\gamma-\mathrm{Fe}_{2} \mathrm{O}_{3}$ (JCPDS file no. 04-0755). The observed diffraction peaks was indicated that $\gamma$ $\mathrm{Fe}_{2} \mathrm{O}_{3}$ mostly exists in face-centered cubic structure. In addition, the diffraction plane of (111) at $2 \theta=37.4^{\circ}$ in the XRD pattern of $\mathrm{Cu}$-isatin Schiff base- $\gamma-\mathrm{Fe}_{2} \mathrm{O}_{3}$ is ascribed to $\mathrm{Cu}$.

The thermogravimetric analysis (TGA) of Cu-isatin Schiff base- $\gamma-\mathrm{Fe}_{2} \mathrm{O}_{3}$ was used to determine the thermal stability and content of organic functional groups on the surface of magnetic nano particles (Fig. 3). TG curve of the catalyst showed the weight loss at around $182{ }^{\circ} \mathrm{C}$, which was related to the adsorbed water molecules on the support. The organic parts were decomposed completely in the temperature range of 200$600{ }^{\circ} \mathrm{C}$.

The metal content of the complex was determined by ICPOES, and showed a value of $0.11 \mathrm{mmol} \mathrm{g}^{-1}$. Elemental analysis showed that the loading of isatin-Schiff base on $\gamma-\mathrm{Fe}_{2} \mathrm{O}_{3}$, was $0.31 \mathrm{mmol} \mathrm{g}^{-1}$ based on the nitrogen and carbon amounts ( $0.86 \%$ and $3.95 \%$, respectively).

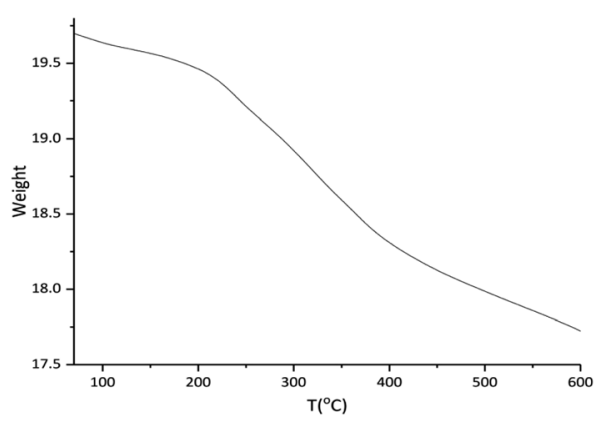

Fig. 3 TGA diagram of $\mathrm{Cu}$-isatin Schiff base $-\gamma-\mathrm{Fe}_{2} \mathrm{O}_{3}$. 


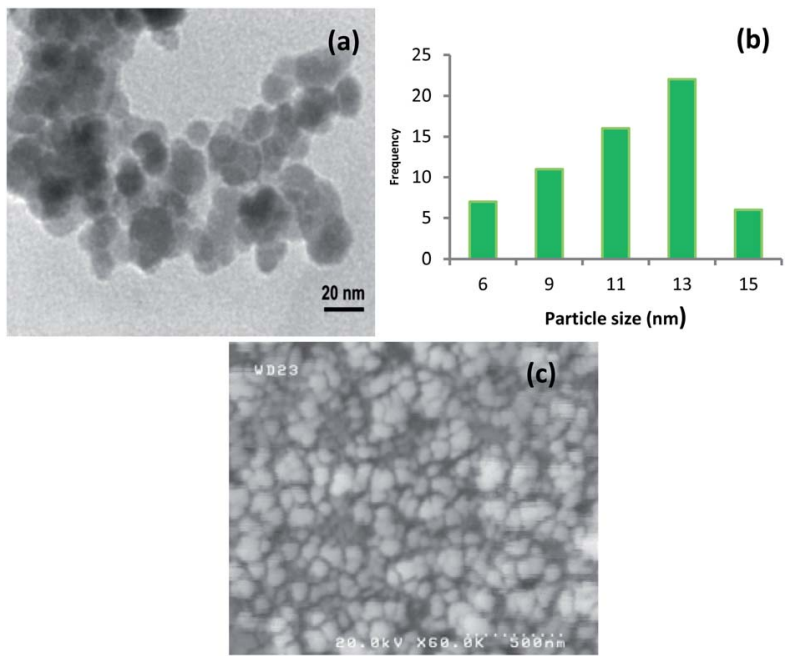

Fig. 4 (a) TEM image of $\mathrm{Cu}$-isatin Schiff base $-\gamma-\mathrm{Fe}_{2} \mathrm{O}_{3}$ and (b) particle size distribution histogram of $\mathrm{Cu}$-isatin Schiff base- $\gamma-\mathrm{Fe}_{2} \mathrm{O}_{3}$. (c) SEM image of $\mathrm{Cu}$-isatin Schiff base- $\gamma-\mathrm{Fe}_{2} \mathrm{O}_{3}$.

The size and morphology of the synthesized catalyst were characterized using TEM and SEM (Fig. 4). The TEM image is clearly showed that $\mathrm{Cu}$-isatin Schiff base- $\gamma-\mathrm{Fe}_{2} \mathrm{O}_{3}$ exhibits spherical morphology with relatively good monodispersity (Fig. 4a). The particle size distribution of Cu-isatin Schiff base$\gamma-\mathrm{Fe}_{2} \mathrm{O}_{3}$ was evaluated using TEM and showed that the average diameter of the particles was $13 \mathrm{~nm}$ (Fig. 4b). The SEM image analysis indicates that the- $\gamma-\mathrm{Fe}_{2} \mathrm{O}_{3}$ nanoparticles are spherical in shape (Fig. 4c).

The saturation magnetization values for $\gamma-\mathrm{Fe}_{2} \mathrm{O}_{3}$ and $\mathrm{Cu}$ isatin Schiff base- $\gamma-\mathrm{Fe}_{2} \mathrm{O}_{3}$ were 68.9 and $65.2 \mathrm{emu} \mathrm{g}^{-1}$, respectively (Fig. 5). A slight decrease of the saturation magnetization of $\mathrm{Cu}$-isatin Schiff base- $\gamma-\mathrm{Fe}_{2} \mathrm{O}_{3}$ was due to the immobilization of $\mathrm{Cu}$ complex on the surface of $\gamma-\mathrm{Fe}_{2} \mathrm{O}_{3}$.

Cu-isatin Schiff base- $\gamma-\mathrm{Fe}_{2} \mathrm{O}_{3}$ was also analyzed by XPS spectroscopy (Fig. 6). The observed characteristic peaks in the XPS elemental survey are attributed to carbon (C 1s), nitrogen (N 1s), oxygen (O 1s), iron, silicon and copper (Fig. 6a). ${ }^{18}$ The $\mathrm{C}$ 1s spectrum (Fig. 6b) showed binding energies of 284.5 (C-C), $285.4(\mathrm{C}=\mathrm{N}), 286.4(\mathrm{C}-\mathrm{N})$ and $288.3 \mathrm{eV}(\mathrm{C}=\mathrm{O}) .{ }^{19}$ Furthermore, high resolution XPS of $\mathrm{N} 1 \mathrm{~s}$ region confirmed the presence of $\mathrm{N}-$

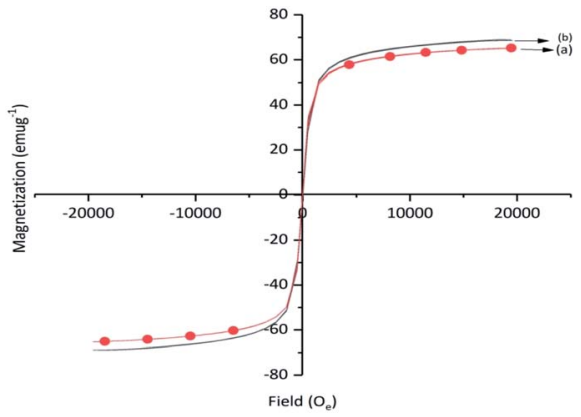

Fig. 5 Magnetization curves of (a) $\mathrm{Cu}$-isatin Schiff base- $\gamma-\mathrm{Fe}_{2} \mathrm{O}_{3}$ and (b) $\gamma-\mathrm{Fe}_{2} \mathrm{O}_{3}$.
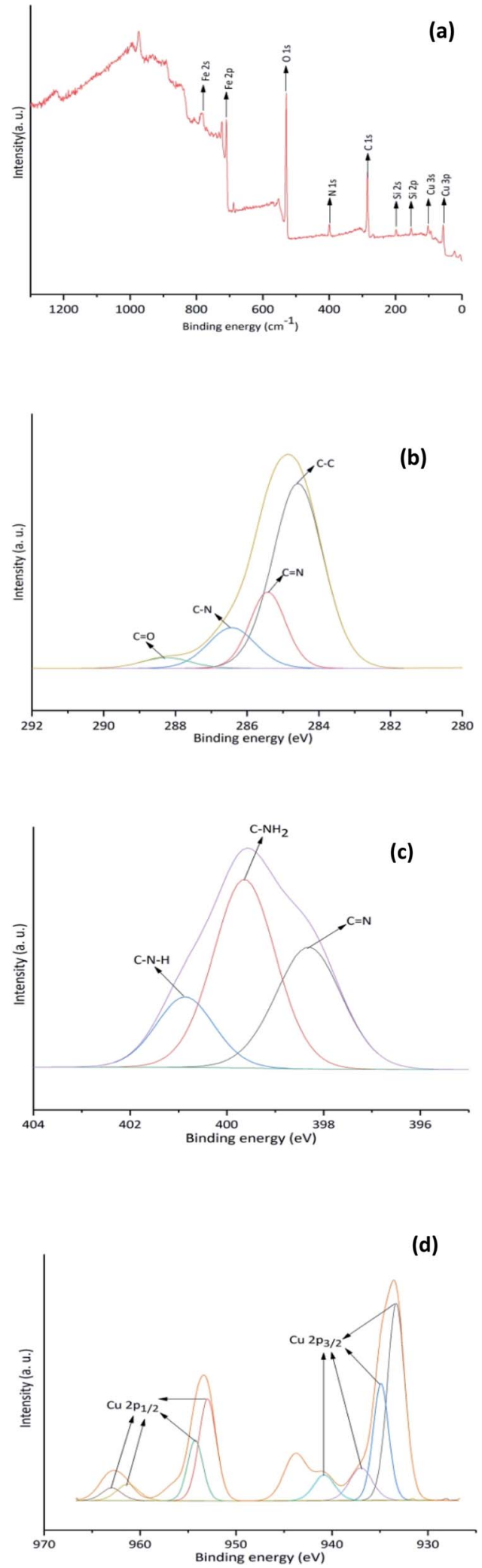

Fig. 6 (a) XPS patterns of the $\mathrm{Cu}$-isatin Schiff base- $\gamma-\mathrm{Fe}_{2} \mathrm{O}_{3}$, (b) $\mathrm{C}$ (1s), (c) N (1s), (d) Cu.

$\mathrm{H}$, imine and $-\mathrm{NH}_{2}$ by revealing three peaks at $400.8,399.6$ and $398.3 \mathrm{eV}$, respectively (Fig. 6c). ${ }^{20}$ In the XPS spectrum of $\mathrm{Cu}$ (Fig. 6d), the presence of binding energies at 933.3 and $940.8 \mathrm{eV}$ 
Table 1 Optimization of the tandem imine formation via auto-hydrogen transfer from benzyl alcohol to nitrobenzene

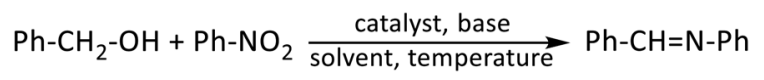

\begin{tabular}{|c|c|c|c|c|c|c|}
\hline 1 & 2 & - & $\mathrm{K}_{2} \mathrm{CO}_{3}$ & 100 & 5 & 42 \\
\hline 3 & 2 & - & $\mathrm{Na}_{2} \mathrm{CO}_{3}$ & 100 & 24 & 35 \\
\hline 4 & 2 & - & $\mathrm{KOH}$ & 100 & 9 & 95 \\
\hline 5 & 2 & - & $\mathrm{NaOH}$ & 100 & 9 & 86 \\
\hline 8 & 2 & $\mathrm{H}_{2} \mathrm{O}$ & $\mathrm{KOH}$ & 80 & 24 & 0 \\
\hline 9 & 2 & Acetonitrile & $\mathrm{KOH}$ & 68 & 24 & Trace \\
\hline 10 & 2 & Benzyl alcohol & $\mathrm{KOH}$ & 100 & 7 & 81 \\
\hline 11 & 2 & $n$-Hexane & $\mathrm{KOH}$ & 50 & 5 & 35 \\
\hline 12 & 2 & Toluene & $\mathrm{KOH}$ & 90 & 3 & 32 \\
\hline 13 & 2 & Ethyl acetate & $\mathrm{KOH}$ & 60 & 24 & Trace \\
\hline 18 & 0 & - & $\mathrm{KOH}$ & 100 & 24 & 21 \\
\hline $19^{b}$ & 1 & - & $\mathrm{KOH}$ & 100 & 24 & 43 \\
\hline $20^{c}$ & 1 & - & $\mathrm{KOH}$ & 100 & 24 & 30 \\
\hline $21^{d}$ & 1 & - & $\mathrm{KOH}$ & 100 & 10 & $0^{e}$ \\
\hline $22^{f}$ & 1 & - & $\mathrm{KOH}$ & 100 & 10 & 0 \\
\hline $22^{g}$ & 1 & - & $\mathrm{KOH}$ & 100 & 10 & 90 \\
\hline $23^{h}$ & 1 & - & $\mathrm{KOH}$ & 100 & 12 & 87 \\
\hline
\end{tabular}

${ }^{a}$ Reaction conditions: nitrobenzene ( $0.5 \mathrm{mmol}$, except for entry 21$)$, benzyl alcohol ( $0.5 \mathrm{mmol}$, except for entry 22$)$, base (0.5 mmol, except for entry 6), solvent (3 mL, entries 7-13). ${ }^{b} \mathrm{CuCl}_{2} \cdot 2 \mathrm{H}_{2} \mathrm{O}$ was used as a catalyst. ${ }^{c}$ Isatin Schiff base- $\gamma-\mathrm{Fe}_{2} \mathrm{O}_{3}$ as a catalyst. ${ }^{d}$ Without nitrobenzene. ${ }^{e}$ Benzaldehyde was obtained as the only product in $60 \%$ yield. ${ }^{f}$ Without benzyl alcohol. ${ }^{g}$ Under $\mathrm{O}_{2} .{ }^{h}$ Under Ar.

$\left(\mathrm{Cu} 2 \mathrm{p}_{3 / 2}\right)$ along with the binding energies at 952.9 and $963.1 \mathrm{eV}$ (Cu 2 $\mathrm{p}_{1 / 2}$ ) could be ascribed to $\mathrm{Cu}$ with (I) oxidation state. The peaks centered at 934.9, $936.9\left(\mathrm{Cu} 2 \mathrm{p}_{3 / 2}\right)$ and 954.2, 961.3 eV $(\mathrm{Cu}$ $2 \mathrm{p}_{1 / 2}$ ) are attributed to the existence of $\mathrm{Cu}(\mathrm{II})$ in the catalyst. ${ }^{21}$

After catalyst characterization, its catalytic activity was studied in the tandem imines formation by auto-hydrogen transfer from alcohols to nitro compounds. At first, to find out the best reaction conditions, a set of factors including base, solvent, temperature and the amount of the catalyst were screened in the reaction of benzyl alcohol and nitrobenzene as the model reaction. The study of the influence of the base, as well as its absence, showed that $\mathrm{KOH}$ rendered the best results (Table 1, entry 4). The solvent dependency of the model reaction was investigated (Table 1, entries 7-13) and found that the reaction proceeded efficiently under solvent-free conditions as green and sustainable reaction conditions. In an effort to optimize the reaction temperature, temperatures below $100{ }^{\circ} \mathrm{C}$ were found to minimize the imines formation (Table 1, entries 14 and 15). Screening the amount of the catalyst showed that decreasing the catalyst amount from 2 to $1 \mathrm{~mol} \%$ led to a negligible decrease in the yield of the product (Table 1, entry 16). Poorer activity was obtained by further lowering the catalyst amount (Table 1, entry 17). To show the role of the catalyst, the reaction was performed in the absence of the catalyst and also in the presence of $\mathrm{CuCl}_{2}$ and isatin Schiff base- $\gamma-\mathrm{Fe}_{2} \mathrm{O}_{3}$ as a copper less analogue of the catalyst (Table 1, entries 18-20). It was found that the desired product was obtained in low yield after $24 \mathrm{~h}$. These findings indicated that a desirable activation of copper was occurred by complexation in the catalyst. The reaction of benzyl alcohol was studied in the presence of the catalyst under optimized reaction conditions (Table 1, entry 21). The results showed that benzyl alcohol was oxidized and produced benzaldehyde in $60 \%$ yield after $10 \mathrm{~h}$. The reaction of nitrobenzene in the presence of the catalyst was also studied and any product was not obtained (Table 1, entry 22). This should be attributed to the lack of benzyl alcohol as a driving force for subsequent reduction of nitro groups. Performing the model reaction under $\mathrm{O}_{2}$ and Ar atmosphere proceeded with no change in the product yields (Table 1, entries 22 and 23) compared with the optimal conditions (Table 1, entry 16), which showed that alcohol dehydrogenized without requiring specific atmospheric conditions.

With an optimized catalytic system in hand (Table 1), we set out to probe versatility of the present method in the direct imine synthesis of various alcohols and nitro compounds by autohydrogen transfer strategy. As depicted in Table 2, the 
Table 2 Tandem imines formation via auto-hydrogen transfer from alcohols to nitro compounds catalyzed by $\mathrm{Cu}$-isatin Schiff base- $\gamma$ $\mathrm{Fe}_{2} \mathrm{O}_{3}$

$$
\mathrm{R}^{1}-\mathrm{CH}_{2}-\mathrm{OH}+\mathrm{R}^{2}-\mathrm{NO}_{2} \underset{\text { solvent-free, } \mathrm{KOH}, 100^{\circ} \mathrm{C}}{\stackrel{\text { Cu-isatin Schiff base }-\mathrm{Fe} \mathrm{O}_{3}(1 \mathrm{~mol} \%)}{\longrightarrow}} \mathrm{R}^{1}-\mathrm{CH}=\mathrm{N}-\mathrm{R}^{2}
$$

\begin{tabular}{|c|c|c|c|c|c|}
\hline Entry $^{a}$ & $\mathrm{R}^{1}$ & $\mathrm{R}^{2}$ & Product & Time (h) & Yield (\%) \\
\hline 1 & $\mathrm{C}_{6} \mathrm{H}_{5}$ & $\mathrm{C}_{6} \mathrm{H}_{5}$ & $\mathbf{a}$ & 10 & 92 \\
\hline 2 & $\mathrm{C}_{6} \mathrm{H}_{5}$ & $4-\mathrm{OH}-\mathrm{C}_{6} \mathrm{H}_{4}$ & b & 8 & 90 \\
\hline 3 & $\mathrm{C}_{6} \mathrm{H}_{5}$ & $4-\mathrm{OMe}-\mathrm{C}_{6} \mathrm{H}_{4}$ & c & 8 & 84 \\
\hline 4 & $\mathrm{C}_{6} \mathrm{H}_{5}$ & $4-\mathrm{Me}-\mathrm{C}_{6} \mathrm{H}_{4}$ & d & 9 & 87 \\
\hline 5 & $\mathrm{C}_{6} \mathrm{H}_{5}$ & $4-\mathrm{Cl}-\mathrm{C}_{6} \mathrm{H}_{4}$ & e & 12 & 71 \\
\hline 6 & $4-\mathrm{Me}-\mathrm{C}_{6} \mathrm{H}_{4}$ & $\mathrm{C}_{6} \mathrm{H}_{5}$ & f & 13 & 91 \\
\hline 7 & $4-\mathrm{Me}-\mathrm{C}_{6} \mathrm{H}_{4}$ & 4-Cl- $\mathrm{C}_{6} \mathrm{H}_{4}$ & g & 12 & 68 \\
\hline 8 & $4-\mathrm{Me}-\mathrm{C}_{6} \mathrm{H}_{4}$ & $4-\mathrm{OMe}-\mathrm{C}_{6} \mathrm{H}_{4}$ & h & 10 & 85 \\
\hline 9 & $4-\mathrm{Me}-\mathrm{C}_{6} \mathrm{H}_{4}$ & $4-\mathrm{Me}-\mathrm{C}_{6} \mathrm{H}_{4}$ & i & 12 & 83 \\
\hline 10 & $4-\mathrm{OMe}-\mathrm{C}_{6} \mathrm{H}_{4}$ & $\mathrm{C}_{6} \mathrm{H}_{5}$ & $\mathbf{j}$ & 12 & 75 \\
\hline 11 & $4-\mathrm{OMe}-\mathrm{C}_{6} \mathrm{H}_{4}$ & $4-\mathrm{Cl}-\mathrm{C}_{6} \mathrm{H}_{4}$ & $\mathbf{k}$ & 13 & 72 \\
\hline 12 & $4-\mathrm{OMe}-\mathrm{C}_{6} \mathrm{H}_{4}$ & $4-\mathrm{OMe}-\mathrm{C}_{6} \mathrm{H}_{4}$ & 1 & 11 & 84 \\
\hline 13 & $4-\mathrm{OMe}-\mathrm{C}_{6} \mathrm{H}_{4}$ & $4-\mathrm{Me}-\mathrm{C}_{6} \mathrm{H}_{4}$ & $\mathbf{m}$ & 14 & 70 \\
\hline 14 & $\mathrm{C}_{6} \mathrm{H}_{5}$ & $\mathrm{CH}_{3}-\mathrm{CH}_{2}^{-}$ & $\mathbf{n}$ & 10 & 72 \\
\hline 15 & $\mathrm{CH}_{3}-\mathrm{CH}_{3}-\mathrm{CH}_{2}-$ & $\mathrm{C}_{6} \mathrm{H}_{5}$ & $\mathbf{o}$ & 12 & 85 \\
\hline
\end{tabular}

${ }^{a}$ Reaction conditions: nitro compound $(1 \mathrm{mmol})$, alcohol $(1 \mathrm{mmol})$, $\mathrm{KOH}(1 \mathrm{mmol})$, solvent-free, catalyst $(1 \mathrm{~mol} \%), 100{ }^{\circ} \mathrm{C}$. Melting points of the solid products were compared with the reported ones in the ESI (Table S1).

reaction of various nitrobenzenes and benzyl alcohols catalyzed by $\mathrm{Cu}$-isatin Schiff base- $\gamma-\mathrm{Fe}_{2} \mathrm{O}_{3}$ gave expected imines $(\mathbf{a}-\mathbf{m})$ in good to high yields (Table 2 , entries 1-13). The reaction of benzyl alcohol with nitroethane as an aliphatic compound and also the reaction of nitrobenzene with 1-butanol as an aliphatic alcohol proceeded well under optimized reaction conditions (Table 2, entries 14 and 15). The imine products in the current study have widespread usages in the synthesis of biologically active compounds with antibacterial and antifungal activities. ${ }^{22}$
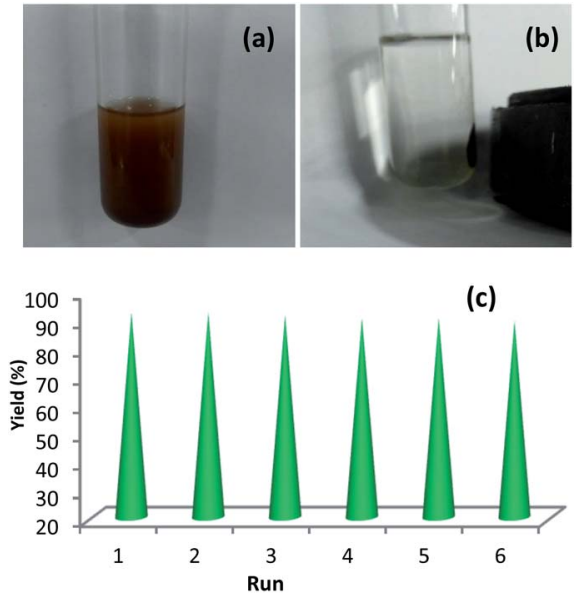

Fig. 7 (a) Reaction mixture after adding EtOAc, (b) isolation of the catalyst by an external magnet (c) reusability of $\mathrm{Cu}$-isatin Schiff base$\gamma-\mathrm{Fe}_{2} \mathrm{O}_{3}$ in the reaction of nitrobenzene and benzyl alcohol at $100{ }^{\circ} \mathrm{C}$ in $10 \mathrm{~h}$.

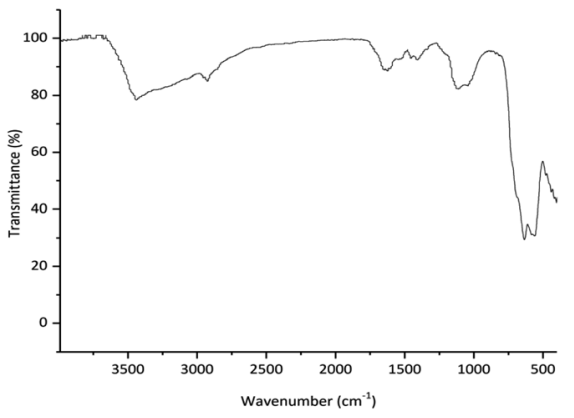

Fig. 8 FT-IR spectrum of the $\mathrm{Cu}$-isatin Schiff base- $\gamma-\mathrm{Fe}_{2} \mathrm{O}_{3}$ after six times reuse.

The recyclability of $\mathrm{Cu}$-isatin Schiff base- $\gamma-\mathrm{Fe}_{2} \mathrm{O}_{3}$ was investigated in a model reaction of benzyl alcohol and nitrobenzene in the auto-hydrogen transfer reaction, under optimized reaction conditions. EtOAc was added to the reaction mixture after $10 \mathrm{~h}$ (Fig. 7a). The catalyst was isolated by an external magnet (Fig. 7b), washed with EtOAc and EtOH $(2 \times 10 \mathrm{~mL})$ and dried under vacuum. The catalyst was successfully recycled for six times. Loss of the catalytic activity was not considerably observed for $\mathrm{Cu}$-isatin Schiff base- $\gamma-\mathrm{Fe}_{2} \mathrm{O}_{3}$ in these reactions (Fig. 7c).

Comparison of FT-IR of the reused catalyst (Fig. 8) with the freshly prepared one (Fig. 1c) indicated that any significant changes in the chemical structure of the catalyst was not observed.

Moreover, TEM and FE-SEM images illustrated that the nanoparticles were still spherical in shape even after six times reuse (Fig. 9a and b) and the mean diameter size of the recycled catalyst was $14 \mathrm{~nm}$ (Fig. 9c).

To study the synthetic applications and practical activity of this protocol, the reaction of benzyl alcohol $(50 \mathrm{mmol})$ and nitrobenzene $(50 \mathrm{mmol})$ was assessed under the optimized
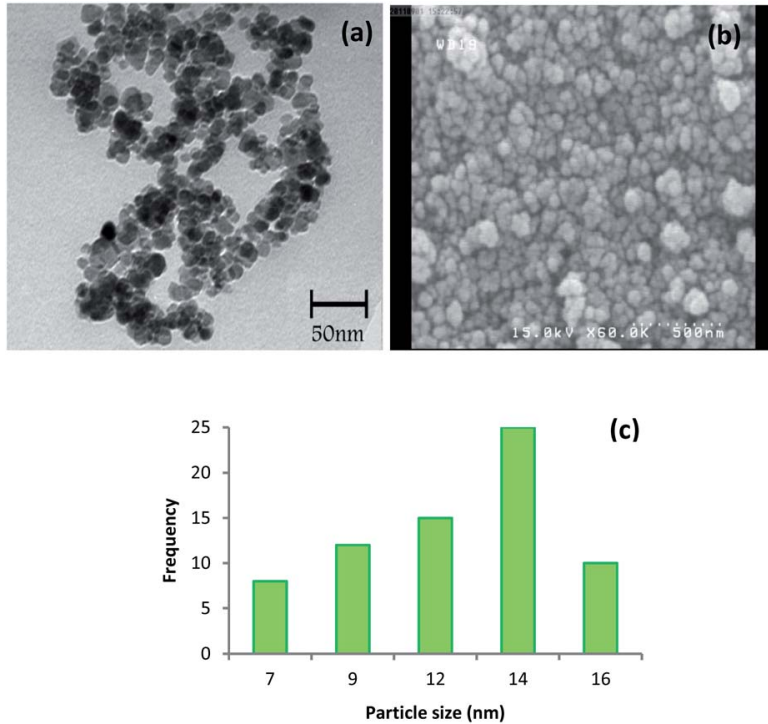

Fig. 9 (a) TEM image, (b) FE-SEM image and (c) size distribution of the $\mathrm{Cu}$-isatin Schiff base- $\gamma-\mathrm{Fe}_{2} \mathrm{O}_{3}$ after six times reuse. 


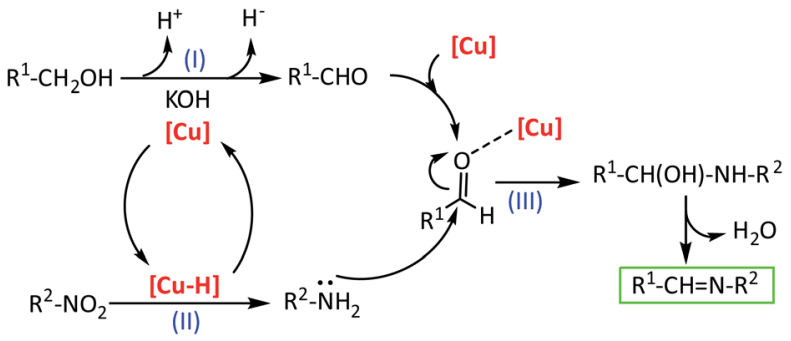

Scheme 2 A plausible mechanism for the tandem reaction catalyzed by $\mathrm{Cu}$-isatin Schiff base- $\gamma-\mathrm{Fe}_{2} \mathrm{O}_{3}$.

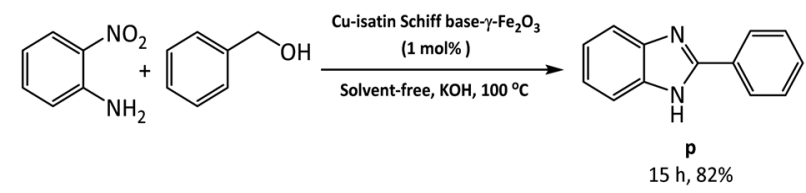

Scheme 3 Tandem reaction of 2-nitroaniline with benzyl alcohol under the optimized reaction conditions.

reaction conditions and the desired product was isolated in $90 \%$ yield after $13 \mathrm{~h}$.

Based on our experiment results and previous literature reports, ${ }^{10 b, 12,13,14,26}$ a reaction mechanism to rationalize the direct imines formation from the reaction of nitroarenes with alcohols was depicted in Scheme 2. First, the alcohol is dehydrogenated to aldehyde in the presence of $\mathrm{Cu}$-isatin Schiff base$\gamma-\mathrm{Fe}_{2} \mathrm{O}_{3}$ as a catalyst promoted by base, releasing proton and hydride (step I). Simultaneously, the hydride is transferred to the copper complex to give a copper-hydride complex. This copper-hydride complex reduces the nitro group to amine via $\mathrm{N}$ phenylhydroxylamine as a well-known intermediate (step II). ${ }^{23}$ In the next step, the nucleophilic attack of the amine to the activated aldehyde by the copper catalyst followed by water elimination gives the imine product (step III). In this mechanism the copper catalyst promoted both the hydrogen transfer from the alcohol to the nitro compounds and also the imine formation from the in situ produced aldehyde and amine. To investigate the mechanism in detail, the reaction of $\mathrm{N}$-phenylhydroxylamine and benzyl alcohol under optimized reaction conditions was employed. The imine was obtained in $80 \%$ yield after $8 \mathrm{~h}$. The reaction of benzaldehyde with aniline was also studied and the desired imine was produced in $93 \%$ yield after $6 \mathrm{~h}$.

The applicability of this method was also examined for the one-pot reaction of 2-nitroaniline with benzyl alcohol under the optimized reaction conditions at the last part of our studies. Benzimidazole (p) was produced in $82 \%$ yields by autohydrogen transfer reaction in the presence of $\mathrm{Cu}$-isatin Schiff base- $\gamma-\mathrm{Fe}_{2} \mathrm{O}_{3}$ (Scheme 3).

To show the merits of the present protocol for the synthesis of imines, we have compared the catalytic activity of $\mathrm{Cu}$-isatin Schiff base- $\gamma-\mathrm{Fe}_{2} \mathrm{O}_{3}$ with those of some reported catalysts in the auto-hydrogen transfer reactions (Table 3). As depicted in Table 3, Cu-isatin Schiff base- $\gamma-\mathrm{Fe}_{2} \mathrm{O}_{3}$ is the most effective catalyst for the reaction of benzyl alcohols and nitrobenzenes. The reported synthetic routes have certain limitations such as requiring high temperature, long reaction times, expensive catalysts, additives, large amount of the catalyst, bimetallic catalysts, especial atmospheric conditions, toxic organic solvents and most importantly use of excess amounts of benzyl alcohol as the reaction solvent. More importantly, our catalyst is a magnetic heterogeneous catalyst and can be easily separated from the reaction mixture using an external magnet.

\section{Experimental}

\section{General procedure for the tandem synthesis of imine from alcohols and nitro compounds}

Cu-isatin Schiff base- $\gamma-\mathrm{Fe}_{2} \mathrm{O}_{3}(1 \mathrm{~mol} \%)$ was added to a mixture of alcohol $(1 \mathrm{mmol})$, nitro compound $(1 \mathrm{mmol})$ and $\mathrm{KOH}(1$ $\mathrm{mmol}$ ) and the resulting mixture was stirred at $100{ }^{\circ} \mathrm{C}$ for an appropriate time (Table 2). After cooling the reaction mixture to

Table 3 Comparison of catalytic activity of $\mathrm{Cu}$-isatin Schiff base- $\gamma-\mathrm{Fe}_{2} \mathrm{O}_{3}$ with some reported catalysts for the auto-hydrogen transfer reactions of alcohols with nitro compounds

\begin{tabular}{|c|c|c|c|c|}
\hline Entry (ref.) & Catalyst (mol\%) & Reaction conditions & Time (h) & Yield (\%) \\
\hline 1 (ref. 10a) & $\mathrm{Pd} / \mathrm{HT}^{a}(2)$ & Toluene, $130{ }^{\circ} \mathrm{C}$ & 24 & $35-93$ \\
\hline 2 (ref. 11) & Ag-MCP-1 ${ }^{b}(25 \mathrm{mg})$ & Toluene, $\mathrm{K}_{2} \mathrm{CO}_{3}$, glycerol, $120^{\circ} \mathrm{C}$ & 12 & $70-99$ \\
\hline 3 (ref. 24) & $\mathrm{Rh} / \mathrm{Au}(0.5)$ & Benzyl alcohol (solvent), $\mathrm{Cs}_{2} \mathrm{CO}_{3}, 100{ }^{\circ} \mathrm{C}$ & 22 & 57 \\
\hline 4 (ref. 25) & Co-N-C/CNT@AC ${ }^{c}(0.4$ g) & Solvent free, $\mathrm{N}_{2}$ atmosphere, $160{ }^{\circ} \mathrm{C}$ & $18-42$ & $12-100$ \\
\hline 5 (ref. 26) & $\mathrm{Ir}^{\mathrm{III}}-\mathrm{Au}^{\mathrm{I}}$ heterodimetallic complex (1) & Benzyl alcohol (solvent), $\mathrm{Cs}_{2} \mathrm{CO}_{3}, 100{ }^{\circ} \mathrm{C}$, aerobic condition & $15-22$ & 4-99 \\
\hline 6 (ref. 14) & $\mathrm{CoO}_{X} @ \mathrm{NC}-800^{d}(10)$ & Toluene, ${ }^{t} \mathrm{BuOK}, 120^{\circ} \mathrm{C}$ & 15 & $57-87$ \\
\hline 7 (ref. 12) & Ir-Pd heterodimetallic catalyst (2) & Benzyl alcohol (solvent), $\mathrm{Cs}_{2} \mathrm{CO}_{3}, 110^{\circ} \mathrm{C}$ & $3-20$ & $16-92$ \\
\hline 8 (ref. 15) & $\mathrm{CuO}-\mathrm{Fe}_{3} \mathrm{O}_{4}(1.3)$ & Toluene, $\mathrm{NaOH}, 130{ }^{\circ} \mathrm{C}$ & $3 \mathrm{~d}$ & $58-84$ \\
\hline 9 (ref. $10 b)$ & Pd/DNA (2.9) & Water, $\mathrm{LiOH} \cdot \mathrm{H}_{2} \mathrm{O}, 50^{\circ} \mathrm{C}, \mathrm{N}_{2}$ balloon & 24 & $51-95$ \\
\hline 10 (ref. 13) & $\mathrm{Au} / \mathrm{Ag}-\mathrm{Mo}-\mathrm{NR}^{e}(40 \mathrm{mg})$ & Toluene, $\mathrm{K}_{2} \mathrm{CO}_{3}$, glycerol, $\mathrm{Ar}, 120^{\circ} \mathrm{C}$ & 24 & $60-98$ \\
\hline 11 (ref. 9) & $\mathrm{RuCl}_{3}(3)$ & $\mathrm{K}_{2} \mathrm{CO}_{3}$, glycerol, $\mathrm{N}_{2}$ atmosphere & 24 & $72-99$ \\
\hline 12 (This work) & $\mathrm{Cu}$-isatin Schiff base- $\gamma-\mathrm{Fe}_{2} \mathrm{O}_{3}(1)$ & Solvent-free, $\mathrm{KOH}, 100^{\circ} \mathrm{C}$ & $8-14$ & $65-92$ \\
\hline
\end{tabular}

${ }^{a}$ Hydrotalcite. ${ }^{b}$ Polyacrylic acid. ${ }^{c} \mathrm{Co}, \mathrm{N}$ and C composite encapsulated carbon nanotube grown in situ on the surface of activated carbon. ${ }^{d}$ Cobalt nanoparticles modified with $\mathrm{N}$-doped hierarchical porous carbon derived from biomass. ${ }^{e} \mathrm{Au} / \mathrm{Ag}-\mathrm{Mo}$ nano-rods. 
room temperature, EtOAc $(5 \mathrm{~mL})$ was added to the reaction mixture. The catalyst was separated by an external magnet, washed with EtOAc $(2 \times 10 \mathrm{~mL})$ and EtOH $(2 \times 10 \mathrm{~mL})$, dried in vacuum and reused. The solvent of the combined organic layer was evaporated under vacuum. Pure products were obtained by recrystallization in EtOH or by column chromatography eluted with $n$-hexane : EtOAc (5:1 or $2: 1) .{ }^{1} \mathrm{H}$ NMR spectra of the products (a, c, $\mathbf{d}, \mathbf{e}, \mathbf{g}, \mathbf{k}$ and $\mathbf{p})$ have been presented in the ESI. $\dagger$

\section{Conclusion}

In summary, in this paper, an efficient method for the synthesis of imines by tandem reaction of various alcohols (primary aromatic and aliphatic) and nitro compounds (aromatic and aliphatic) was developed via auto-hydrogen transfer reaction, catalyzed by $\mathrm{Cu}$-isatin Schiff base- $\gamma-\mathrm{Fe}_{2} \mathrm{O}_{3}$ as a nanomagnetically reusable and inexpensive catalyst under solvent-free conditions. Good to high yields of imines were achieved under mild reaction conditions without requiring any additive. After EtOAc was added to the reaction mixture, the catalyst was easily isolated by using an external magnet and reused successfully for six runs without any significant changes on the chemical structure of the catalyst. This catalytic system had the merits of cost effectiveness, environmental benignity, excellent recyclability and good reproducibility for the direct synthesis of imines from alcohols and nitro compounds without requiring high temperature, long reaction times, expensive catalysts, additives, large amounts of the catalyst, bimetallic catalysts, especial atmospheric conditions, hydrogen gas, toxic organic solvents and most importantly use of excess amounts of benzyl alcohol as the reaction solvent.

\section{Conflicts of interest}

There are no conflicts to declare.

\section{Acknowledgements}

Financial support of this project by University of Birjand Research Council is acknowledged. Access to the XPS facilities of University of Alicante is appreciated.

\section{References}

1 (a) A. Jarrahpour, P. Shirvani, V. Sinou, Ch. Latour and J. M. Brunel, Med. Chem. Res., 2016, 25, 149; (b) M. S. Kiakhani and S. Safapour, Clean Technol. Environ. Policy, 2015, 17, 1019; (c) W. A. Zoubi, S. G. Mohamed, A. A. S. Al-Hamdani, A. P. Mahendradhany and Y. G. Ko, RSC Adv., 2018, 8, 23294; (d) M. Jafari, M. Hasanzadeh, R. Karimian and N. Shadjou, Microchem. J., 2019, 147, 741.

2 (a) Y. Feng, J. Yin, Sh. Liu, Y. Wang, B. Li and T. Jiao, ACS Omega, 2020, 7, 3725; (b) Y. Yamashita, H. Suzuki, I. Sato, T. Hirata and S. Kobayashi, Angew. Chem., Int. Ed., 2018, 57, 6896; (c) M. Bai, B. Cui, J. Zuo, J. Zhao, Y. You, Y. Chen, X. Xu, X. Zhang and W. Yuan, Tetrahedron, 2015, 71, 949; (d) H. Luo, K. Chen, H. Jiang and S. Zhu, Org. Lett., 2016, 20, 5208.

3 (a) W. Qin, S. Long, M. Panunzio and S. Biondi, Molecules, 2013, 18, 12264; (b) R. D. Patil and S. Adimurthy, Asian J. Org. Chem., 2013, 2, 726.

4 G. J. Chen, H. C. Ma, W. L. Xin, X. B. Li, F. Z. Jin, J. S. Wang, M. Y. Liu and Y. B. Dong, Inorg. Chem., 2017, 56, 654.

5 G. M. Zhao, H. L. Liu, X. R. Huang, D. D. Zhang and X. Yang, RSC Adv., 2015, 5, 22996.

6 S. Mandal, S. Maity, S. Saha and B. Banerjee, RSC Adv., 2016, 6, 73906.

7 K. Wang, W. Gao, P. Jiang, K. Lan, M. Yang, X. Huang, L. Ma, F. Niu and R. Li, Mol. Catal., 2019, 456, 43.

8 H. Liu, G. K. Chuah and S. Jaenicke, Phys. Chem. Chem. Phys., 2015, 17, 15012.

9 D. Tan, H. Li, D. J. Young and J. Long, Tetrahedron, 2016, 72, 4169.

10 (a) J. Chen, S. Huang, J. Lin and W. Su, Appl. Catal., A, 2014, 470, 1-7; (b) L. Tang, H. Sun, Y. Li, Z. Zha and Z. Wang, Green Chem., 2012, 14, 3423.

11 U. Mandi, A. S. Roy, S. K. Kundu, S. Roy, A. Bhaumik and S. M. Islam, J. Colloid Interface Sci., 2016, 472, 202.

12 A. Zanardi, J. A. Mata and E. Peris, Chem.-Eur. J., 2010, 16, 10502.

13 X. Cui, C. Zhang, F. Shi and Y. Deng, Chem. Commun., 2012, 48, 9391.

14 T. Song, Y. Duan, X. Chen and Y. Yang, Catalysts, 2019, 9, 116.

15 J. M. Perez, R. Cano, M. Yus and D. J. Ramon, Eur. J. Org. Chem., 2012, 24, 4548.

16 (a) S. Sobhani, A. Habibollahi and Z. Zeraatkar, Org. Process Res. Dev., 2019, 23, 1321; (b) H. H. Moghadam, S. Sobhani and J. M. Sansano, ACS Omega, 2020, 5, 18619; (c) A. Khazaee, R. Jahanshahi, S. Sobhani, J. Skibsted and J. M. Sansano, Green Chem., 2020, 22, 4604; (d) The method for the preparation of the catalyst is explained in the ESI. $\dagger$

17 S. Sobhani, S. Asadi, M. Salimi and F. Zarifi, J. Organomet. Chem., 2016, 822, 154.

18 M. Niakan, Z. Asadi and M. M. Farahani, Appl. Surf. Sci., 2019, 481, 394.

19 B. Huang, J. Chen, S. Zhan and J. Ye, J. Electrochem. Soc., 2016, 163, G26.

20 X. Zhang, X. Hu, P. Guan, N. Zhang, J. Li and C. Du, J. Mater. Sci., 2017, 52, 4713.

21 Y. Liu, L. Ma, D. Zhang, G. Han and Y. Chang, RSC Adv., 2017, 7, 12027.

22 L. Ravishankar, S. A. Patwe, N. Gosarani and A. Roy, Synth. Commun., 2010, 40, 3177.

23 X. Cui, Y. Zhang, F. Shi and Y. Deng, Chem.-Eur. J., 2011, 17, 2587.

24 M. Böhmer, F. Kampert, T. T. Y. Tan, G. G. Barrios, E. Peris and F. E. Hahn, Organometallics, 2018, 37, 4092.

25 D. Liu, P. Yang, H. Zhang, M. Liu, W. Zhang, D. Xu and J. Gao, Green Chem., 2019, 21, 2129.

26 S. Sabater, J. A. Mata and E. Peris, Chem.-Eur. J., 2012, 18, 6380 . 